\title{
MODELO DE GESTÃO DE DRENAGEM URBANA APLICADO À BACIA DO UNA EM BELÉM-PA
}

\author{
Marco Valério de Albuquerque VINAGRE ${ }^{1}$ \\ Leonardo Augusto Lobato BELLO ${ }^{2}$ \\ Andréia do Socorro Condurú de Sousa CARDOSO ${ }^{3}$ \\ Paulo Guilherme Porto de Oliveira FOLHA NETO ${ }^{4}$ \\ Vitor Gantuss RABÊLO ${ }^{5}$
}

\begin{abstract}
${ }^{1}$ Engenheiro de Infraestrutura (ITA). Doutor em Engenharia de Recursos Naturais (UFPA). Professor Titular da Universidade da Amazônia (UNAMA). Email: valeriovinagre@ gmail.com.

${ }^{2}$ Engenheiro Civil ( UNAMA). Doutor em Engenharia Civil - Geotecnia (PUC-RIO). Professor Titular da UNAMA e coordenador do Programa de Mestrado em Desenvolvimento e Meio Ambiente Urbano da UNAMA. Email: lalbello1402@gmail.com.

${ }^{3}$ Engenheira Civil (UFPA). Doutora em Desenvolvimento Sustentável do Trópico Úmido (UFPA) Professor Titular da Universidade da Amazônia (UNAMA). Email: aconduru@ globo.com.

${ }^{4}$ Engenheiro Civil ( UNAMA). Email: folhaneto@ hotmail.com.

${ }^{5}$ Engenheiro Civil (UNAMA) com período sanduíche de um ano na University of Western Australia (UWA). Email: vitorgantuss@globo.com.
\end{abstract}

Recebido em: 05/11/2016 - Aprovado em: 18/03/2017 - Disponibilizado em: 01/07/2017

\section{RESUMO:}

Em um contexto de crescimento demográfico e de urbanização desordenado, observa-se aumento da impermeabilização do solo, com aumento do escoamento superficial e diminuição da infiltração natural de águas de chuva, que associados ausência de políticas públicas efetivas de planejamento urbano incluindo drenagem urbana, conduzem a freqüentes inundações urbanas. Em Belém-PA o fenômeno de transbordo de canais nos períodos chuvosos ocorre com frequência. Desta forma, este trabalho tem por objetivo analisar a funcionalidade e o comportamento do sistema de drenagem da Bacia do Una, localizado em Belém-PA, com o auxílio do modelo computacional hidrológico Storm Water Management Model - SWMM, buscando a melhor representação dos processos envolvidos no escoamento pluvial. A bacia do Una ocupa área de 3.035 hectares, cerca de $60 \%$ da área total de Belém (PA), e para este trabalho, essa bacia foi dividida em 19 sub-bacias. Para simular-se o comportamento hidráulico da bacia sob o efeito de evento climático real, utilizaram-se dados de chuva severa ocorrida no dia 9/05/2011, com precipitação total de $62 \mathrm{~mm}$ com três horas de duração. Como resultado, foram identificados pontos críticos passíveis de transbordamentos e alagamentos, assim sugerindo ser necessária a adição de reservatórios de detenção ao sistema.

Palavras-Chave: Urbanização. SWMM. Bacia do Una.

\section{STORM WATER MANAGEMENT MODEL APPLIED TO UNA BASIN IN BELEM-PA}

\begin{abstract}
:
In a context of demographic growth and disorderly urbanization process, it is observed the soil tends to become waterproof, increasing the surface flow and decreasing the natural absorption of rainfall, which associated with the lack of effective public policies of urban planning, including urban drainage, leads to the occurrence of frequent floods in urban areas. In Belém-PA the phenomenon of channels overflow in the rainy season are occurring frequently. Thus, this paper presents as perspective, analyze the functionality and the drainage system behavior of Una basin, located in Belem/Para, using the computational hydrological model Storm Water Management Model - SWMM, searching for a best representation of the processes involved in storm water runoff. The Uma basin occupies area of 3.035 hectares, which equals about $60 \%$ of all the Belem (PA) basins, and for this work, it was divided into 20 sub-basins. For simulating the hydraulic behavior of the basin under real weather event, it was used severe rainfall data held on 09/05/2011, with a total rainfall of $62 \mathrm{~mm}$ in three hours. As a result, critical points that could overflow and flooding were identified, thus suggesting that required the addition of detention basins to the system.
\end{abstract}

Keywords: Urbanization. SWMM. Una basin. 


\section{INTRODUÇÃO}

Segundo IBGE (2014) em 2010 o

Brasil tinha 190 milhões de habitantes, sendo o maior contingente populacional concentrado em áreas urbanas, e as projeções apontam que até 2020 a população urbana terá atingido o percentual de $90 \%$ da total. Belém é a $11^{\mathrm{a}}$ capital brasileira mais populosa e a 2.a maior da Região Norte, com cerca de 1,3 milhões de habitantes. Como conseqüência da crescente urbanização, aumenta a demanda por serviços públicos de água potável, esgotamento sanitário, drenagem pluvial, limpeza pública, energia elétrica, pavimentação, iluminação pública, sistemas de transportes, edificações em geral, etc. Quanto maior a urbanização maior a intervenção humana, com desvio de rios, substituição de drenagem natural por artificial, poluição, etc. O solo, por sua vez, sofre impermeabilização (pavimentos, edificações, etc.), alterando assim o escoamento hidrológico natural, visto que parcela significativa de precipitação passa a escoar superficialmente, necessitando de sistemas eficientes de drenagem de águas pluviais urbanas, para prevenir inundações, alagamentos, deslizamentos de terra, etc. Assim os sistemas de drenagens urbanos precisam ser constantemente avaliados, na perspectiva de se auferir dados que apontem pontos críticos passiveis de transbordos e, desta forma, contribuir para a criação de medidas preventivas à ocorrência de alagamentos.
Segundo Tucci (2002), os prejuízos devidos às inundações na drenagem urbana nas cidades brasileiras têm aumentado exponencialmente, reduzindo a qualidade de vida e o valor das propriedades. Este processo é decorrência da urbanização e a consequente impermeabilização junto com a canalização do escoamento pluvial.

Conforme Cardoso et al. (2014), do ponto de vista ambiental, a falta de permeabilidade do solo contribui para sobrecarga no sistema de drenagem, reduzindo a qualidade de vida ambiental e humana nas áreas urbanas e reforçando a incompatibilidade entre a legislação urbanística e ambiental.

A drenagem eficiente de águas pluviais resulta na minimização de riscos de alagamentos e inundações bem como na diminuição de ocorrências de doenças transmitidas por meio hídrico. Esse trabalho se justifica por sua utilidade, na medida em que consiste em apresentar resultados de uma simulação do comportamento hidrológico da bacia em estudo por meio do modelo hidrológico computacional SWMM, tendo como perspectiva identificar e analisar possíveis pontos críticos passíveis de transbordamentos e sua capacidade de escoamento quando submetido a chuvas severas. Esses estudos podem auxiliar na concepção de medidas preventivas e corretivas como manutenção dos canais que apresentarem pontos críticos, limpeza pública 
intensiva de resíduos sólidos, atenção diferenciada dos governantes nas localidades adjacentes passíveis de alagamentos, ou mesmo educação ambiental aos moradores do entorno.

Neste aspecto o presente trabalho visa estudar o comportamento hidráulico do sistema de drenagem pluvial urbano da bacia do Una, localizado em Belém/PA, por meio de simulação computacional efetuada com a assistência do software SWMM para estudar e avaliar o comportamento hidrológico dessa bacia.

\section{PROCEDIMENTOS METODOLÓGICOS}

\section{Caracterização da área de estudo}

A bacia do Una situa-se na cidade de Belém-PA, cuja localização geográfica apresenta-se na Figura 1 a seguir.

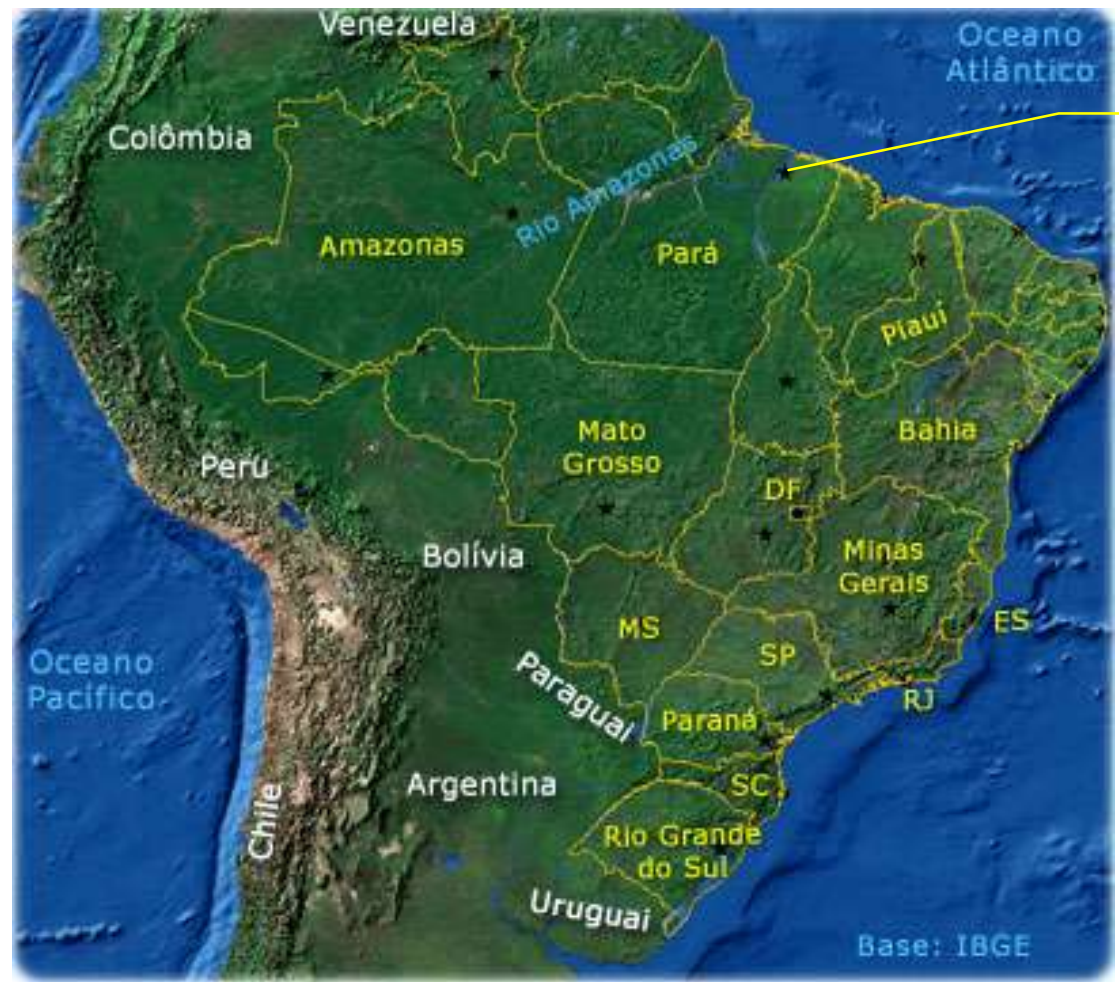

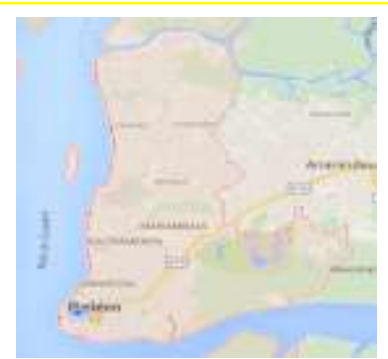

Belém-PA

Figura 1 - Mapa com localização da cidade de Belém-PA. Fonte: Adaptado de IBGE(2016) e PMB(2015).

O município de Belém (PA) situa-se entre as coordenadas geográficas $01^{\circ} 22^{\prime} 0,40^{\prime \prime} \mathrm{S} \quad$ e $\quad 01^{\circ} 27^{\prime} 21,04^{\prime \prime} \mathrm{S} ; \quad$ e $48^{\circ} 26^{\prime} 11,53^{\prime \prime} \mathrm{W}$ e $48^{\circ} 28^{\prime} 27,56^{\prime \prime} \mathrm{W}$. Apresenta precipitação média anual de $2834 \mathrm{~mm}$. Deste total, $71 \%$ ocorrem no período chuvoso de dezembro a maio, e $29 \%$ de junho a novembro (RIBEIRO et al., 2015).

A área continental do município de Belém (PA) apresenta uma extensão territorial de cerca de 6.000 ha. Segundo PMB (2015), Belém possui 14 (quatorze) bacias hidrográficas, sendo que a maior parte da área continental do município encontra-se em 
cotas inferiores a 4,00 (quatro) metros, o que impõe a esses terrenos riscos de inundações.
A Figura 2 apresenta o complexo de bacias hidrográficas de Belém (PA).

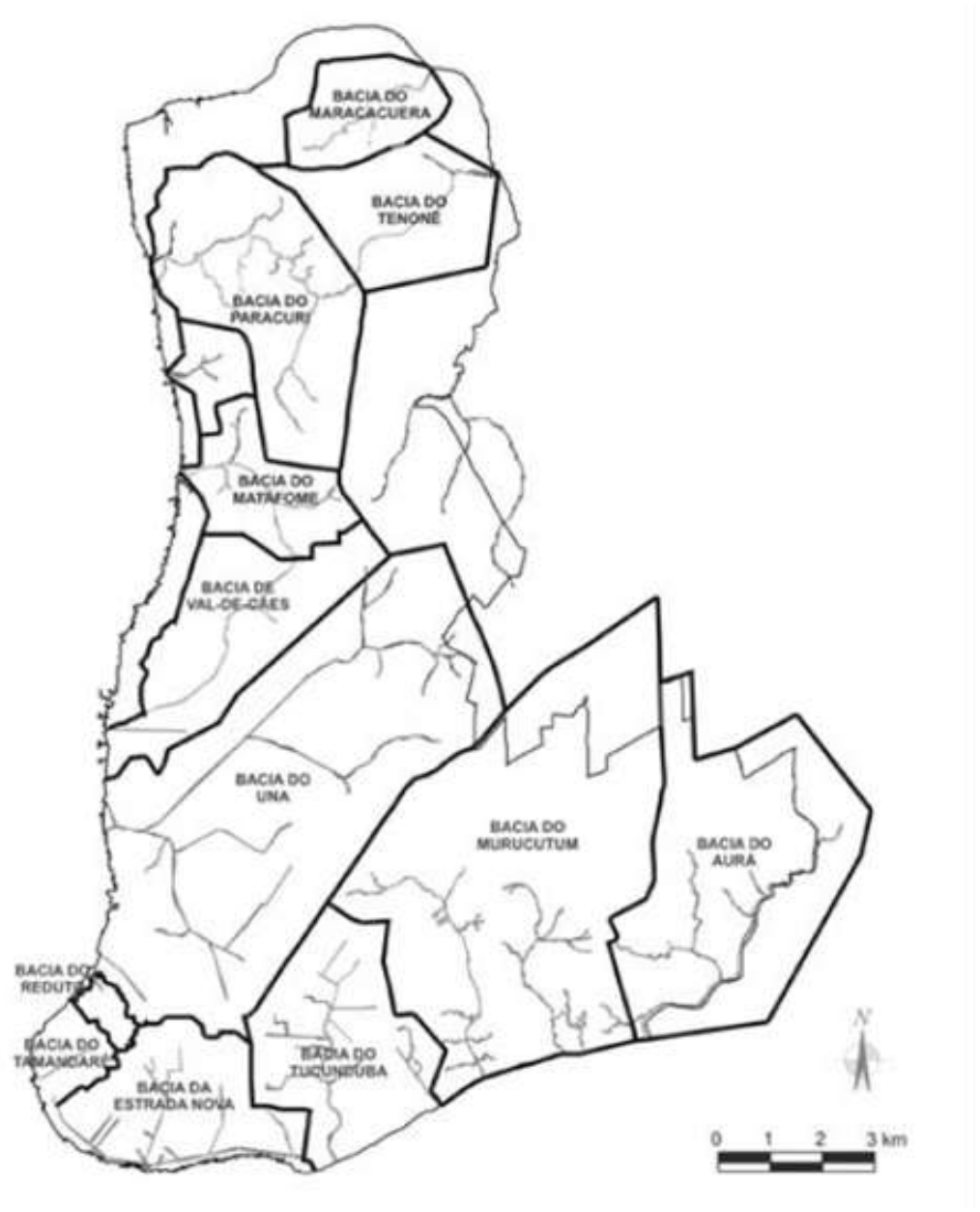

Figura 2 - Bacias hidrográficas no Município de Belém. Fonte: PMB (2015)

O solo da Bacia do Una, segundo Brasil (2004) constitui-se de aluviões recentes (argila, areia e cascalho) com espessura de até $20 \mathrm{~m}$, apresentando restos de matéria orgânica que formam depósitos superficiais às margens dos igarapés e caracterizado por planícies de várzeas sujeitas a inundações periódicas. Destaca Silva (2004) que a execução de obras de engenharia como implantação de canais e vias marginais é um grande desafio, pois envolve escavações e aterros em solos muito moles.
Segundo Ribeiro et al. (2015) a bacia do Una apresenta amplitude altimétrica de $35 \mathrm{~m}$, com altitude mínima de $5 \mathrm{~m}$, média de 22,5m e máxima de 40m, e a relação de relevo é de $4,46 \mathrm{~m} / \mathrm{km}$, pouco declivoso, onde $60 \%$ mostra-se plano (declividade de 0 a $3 \%$ ), apresentando escoamento lento, pois a amplitude altimétrica e relação de relevo definem, em parte, a velocidade de escoamento. Destaca-se que, por essa Bacia apresentar área predominantemente plana e quase toda urbanizada é muito propicia a 


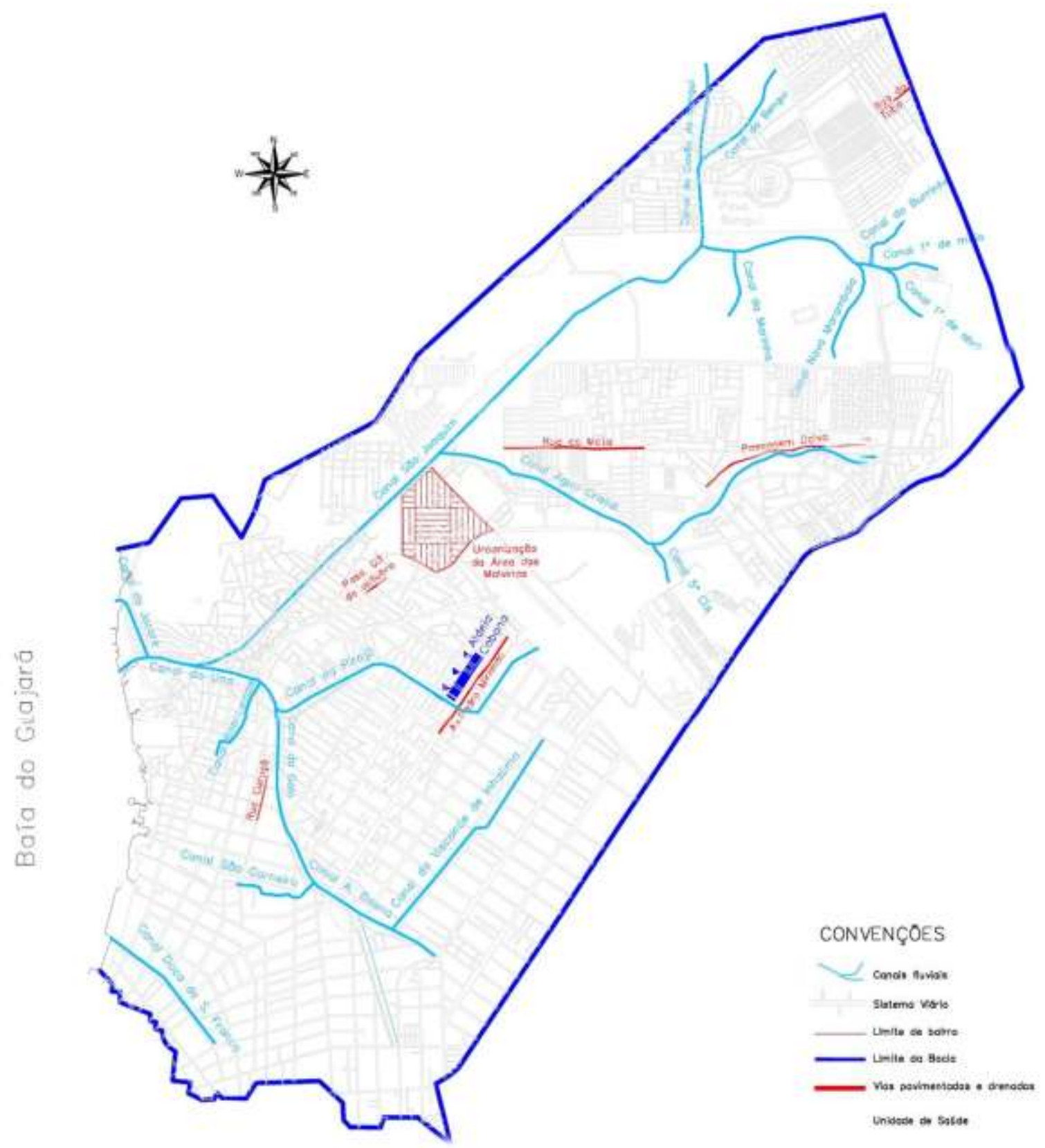

Figura 3 - Mapa da Bacia do Una

Fonte: Leme Engenharia (2001, apud BRASIL, 2004).

De acordo com PMB (2015), a bacia

do Una apresenta área aproximada de 3.035 ha. É a maior bacia urbana de Belém-PA e sua área corresponde a $60 \%$ da área urbana dessa cidade. Até 2010 essa bacia já possuía no seu entorno e bairros adjacentes, segundo IBGE (2011), 613.373 habitantes, correspondente a
44\% da população total de Belém.

Visando solucionar diversos problemas decorrentes do processo de ocupação informal iniciado em 1950 e intensificado na década de 1970, a Bacia do Una passou por um importante processo de reformulação urbana denominado de Projeto 
de Macrodrenagem da Bacia do Una-PMBU, executado em pelo Governo do Estado do Pará em parceria com a Prefeitura Municipal de Belém e financiado pelo Banco Interamericano de Desenvolvimento - BID. Essa obra de teve início no ano de 1992 e término em 2004. A reformulação da bacia não foi apenas uma complexa obra de engenharia para atender somente questões de ordem sanitária, mas sim um empreendimento fundamentado sobre três vertentes: o saneamento básico, a renovação urbana e a promoção socioeconômica, visando a melhoria da qualidade de vida de cerca de 600 mil pessoas, distribuídas nos 20 bairros abrangidos pela bacia.

O saneamento básico contemplado no projeto foi desenvolvido no sentido de implantar sistemas para evitar inundações, erosões e assoreamentos, permitir a construção de interceptores de esgoto e avenidas sanitárias correspondentes, com amplo reflexo na cidade de Belém (PA). Para a execução desse projeto, foi necessária a dragagem e retificação de igarapés e canais da bacia, com o propósito de melhorar o escoamento, evitando perda de carga ao longo do seu trajeto.

As figuras 4 e 5 mostram imagens da situação atual de trechos de canais da bacia do Una. Nelas é possível observar a falta de manutenção dos canais inclusive com lixo doméstico no entorno e dentro dos canais.

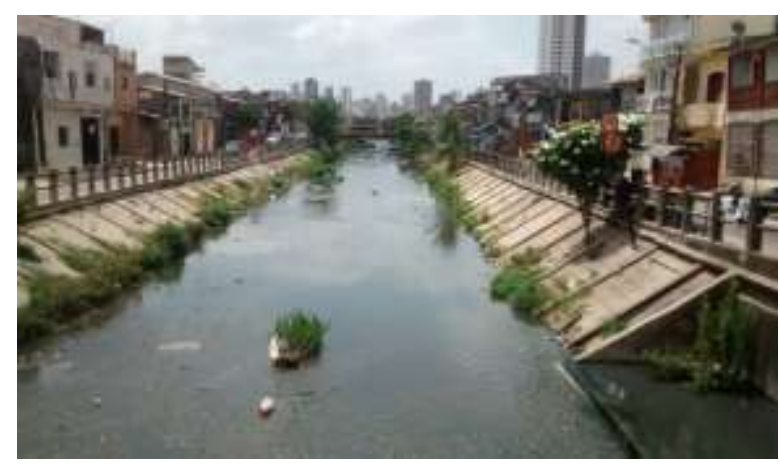

Figura 4 - Canal Visconde de Inhaúma.

Fonte: Autores, 2015

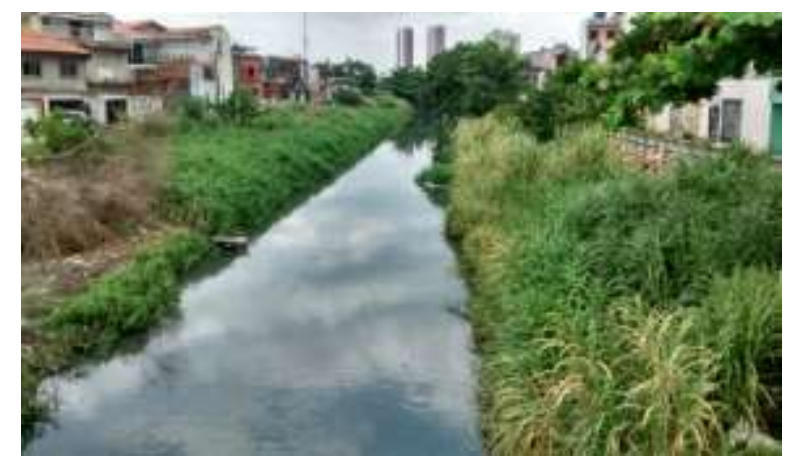

Figura 5 - Canal Antônio Baena Fonte: Autores, 2015.

\section{As Figuras 6 e 7 mostram} alagamentos ocorridos na bacia do Una.

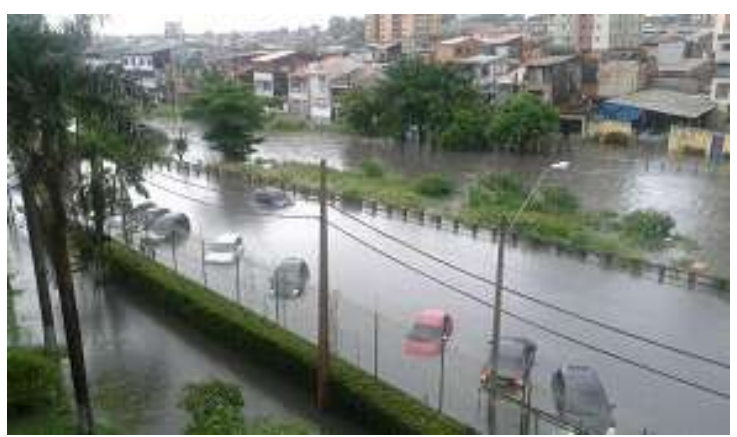

Figura 6 - Canal Antônio Baena transbordando. Fonte: Autores, 2015 
Figura 7 - Alagamento de residência

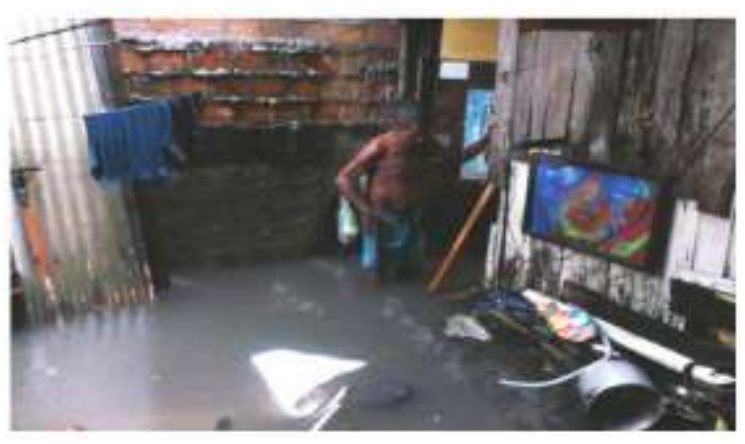

Figura 7 - Alagamento de residência

Fonte: FMPBU (2015).

\section{Simulação no SWMM}

O software Storm Water Management Model - SWMM, em português Modelo de Gestão de Drenagem Urbana, constitui-se em modelo hidrológico de código fonte aberto, desenvolvido em 1971 pela Agência de Proteção Ambiental dos Estados Unidos. Segundo Garcia (2005) é o aplicativo mais utilizado para simulação de drenagem urbana.

Trata-se de um modelo físico, distribuído, de simulação temporal discreta, onde uma bacia hidrográfica é representada por uma série de elementos de sub-bacias, canais ou condutos, permitindo a simulação contínua de eventos sendo capaz de representar uma série de processos hidrológicos (BELING, 2013, p.30).

Esse modelo tem muitas utilidades, sendo capaz de descrever variados processos hidrológicos como escoamento superficial, infiltração, contribuição de águas subterrâneas, propagação da vazão, acúmulo superficial, e propagação da qualidade da água (SHINMA, 2011).

Segundo Targa et al.(2012), para a bacia do Igarapé do Tucunduba em Belém-PA, os coeficientes de escoamento superficial C variaram na média de 0,$30 ; 0,41 ; 0,72$ a 0,73 , respectivamente, para os anos de 1972, 1977, 1998 e 2006, em função do crescimento da urbanização. Com base nesse estudo, para impermeabilização do pavimento urbano da bacia do Una, foi considerado o coeficiente de escoamento superficial $\mathrm{C}=73 \%$. A declividade média dos leitos dos canais assumida foi $i=$ $0,01 \mathrm{~m} / \mathrm{m}$. Os coeficientes de Manning $(n)$ foram adotados segundo o material do revestimento e o estado de conservação médio do canal, conforme segue:

- Leito pedroso e talude vegetado bem conservado $n=0,026$; mal conservado $n=0,040$, média $n=0,33$;

Concreto bem conservado $n=0,012$; mal conservado $n=0,018$, média $n=0,15$.

Os procedimentos para o lançamento dos dados necessários para efetuar-se a simulação da bacia do Una no SWMM são descritos em seguida. A bacia do Una foi discretizada em 19 sub-bacias e, em seguida dados como comprimento, seções, coeficientes de rugosidade de Manning médios, declividades, estado de conservação dos canais; série temporal, cotas do radier nas junções, dentre outras informações. A Tabela 1 relaciona sub-bacias, áreas, canais e extensões. 
Tabela 1 - Sub-bacias e canais da bacia do Una.

\begin{tabular}{|c|c|c|c|c|c|c|c|}
\hline $\begin{array}{l}\text { SUB- } \\
\text { BA- } \\
\text { CIA }\end{array}$ & $\begin{array}{c}\text { ÁREA } \\
\text { (ha) }\end{array}$ & $\begin{array}{c}\text { EXU- } \\
\text { TÓRIO }\end{array}$ & CANAL & $\begin{array}{l}\text { TRECHO } \\
\text { JUSANTE }\end{array}$ & $\begin{array}{l}\text { NÓS INI- } \\
\text { CIAL E } \\
\text { FINAL }\end{array}$ & $\begin{array}{l}\text { EXTEN- } \\
\text { SÃO (m) }\end{array}$ & $n$ \\
\hline S1 & 32,09 & N1 & Nova Marambaia & $\mathrm{T} 1$ & $\mathrm{~N} 1-\mathrm{N} 2$ & 205,39 & 0,033 \\
\hline $\mathrm{S} 2$ & 30,23 & $\mathrm{~N} 2$ & Nova Marambaia & $\mathrm{T} 2$ & $\mathrm{~N} 2-\mathrm{N} 3$ & 534,74 & 0,033 \\
\hline S3 & 82,95 & N3 & Nova Marambaia & $\mathrm{T} 3$ & $\mathrm{~N} 3-\mathrm{N} 4$ & 914,94 & 0,033 \\
\hline S4 & 236,6 & N4 & São Joaquim & $\mathrm{T} 4$ & N4-N5 & 671,51 & 0,033 \\
\hline S5 & 75,31 & N5 & São Joaquim & T5 & N5-N6 & $1.509,44$ & 0,033 \\
\hline S6 & 295,09 & N6 & São Joaquim & T6 & N6-N7 & 646,14 & 0,033 \\
\hline S7 & 410,8 & N7 & São Joaquim & $\mathrm{T} 7$ & N7-N8 & $1.231,54$ & 0,015 \\
\hline S8 & 370,17 & N8 & São Joaquim & $\mathrm{T} 8$ & N8-N9 & $1.385,33$ & 0,033 \\
\hline S9 & 83,43 & N9 & Una & T9 & N9-N10 & 501,28 & 0,033 \\
\hline S10 & 4,54 & N10 & Una & $\mathrm{T} 10$ & N10-E1 & 280,51 & 0,033 \\
\hline S11 & 142,29 & N11 & Nova Marambaia & $\mathrm{T} 11$ & $\mathrm{~N} 11-\mathrm{N} 2$ & 477,97 & 0,033 \\
\hline S12 & 21,81 & N12 & Bengui & $\mathrm{T} 12$ & N12-N4 & 712,20 & 0,015 \\
\hline S13 & 168,83 & N13 & Água Cristal & T13 & N13-N7 & $1.953,94$ & 0,033 \\
\hline S14 & 352,98 & N14 & Pirajá & $\mathrm{T} 14$ & N14-N18 & 893,39 & 0,033 \\
\hline S15 & 265,54 & N15 & Visconde de Inhaúma & $\mathrm{T} 15$ & N15-N16 & $1.109,07$ & 0,015 \\
\hline S16 & 63,93 & N16 & Antônio Baena & $\mathrm{T} 16$ & $\mathrm{~N} 22-\mathrm{N} 21$ & 458,72 & 0,015 \\
\hline S17 & 96,06 & N17 & Galo & $\mathrm{T} 17$ & N21-N16 & $1.537,06$ & 0,033 \\
\hline S18 & 105,08 & N18 & Una & $\mathrm{T} 18$ & N18-N9 & 712,65 & 0,015 \\
\hline S19 & 197,11 & N19 & São Carneiro & T19 & N19-N17 & 643,63 & 0,015 \\
\hline
\end{tabular}

Fonte: Autores, 2016

Para este estudo, foram considerados os principais canais da bacia do Una, compreendendo extensão de 16.379,45 m e uma área de 3.034,84 ha. Partes dos canais encontram-se revestidos em concreto, outros trechos com revestimento natural dos taludes e, uma pequena parcela, apresenta-se revestido com gabião.

Para a realização do estudo de simulação hidrodinâmica da bacia, utilizaram-se dados pluviométricos referentes a Belém (PA), fornecidos pelo Instituto Nacional de Meteorologia -INMET, onde há registro de estação pluviométrica da cidade durante o período de chuvas. Assim, tendo em vistas simular-se o comportamento hidráulico da bacia em evento climático real, utilizaram-se dados da chuva severa ocorrida no dia 9/05/2011, com precipitação total de $62 \mathrm{~mm}$ com três horas de duração.

A figura 8 apresenta os dados da chuva citada que alimentaram a série temporal ST1 correspondente lançada no SWMM. 


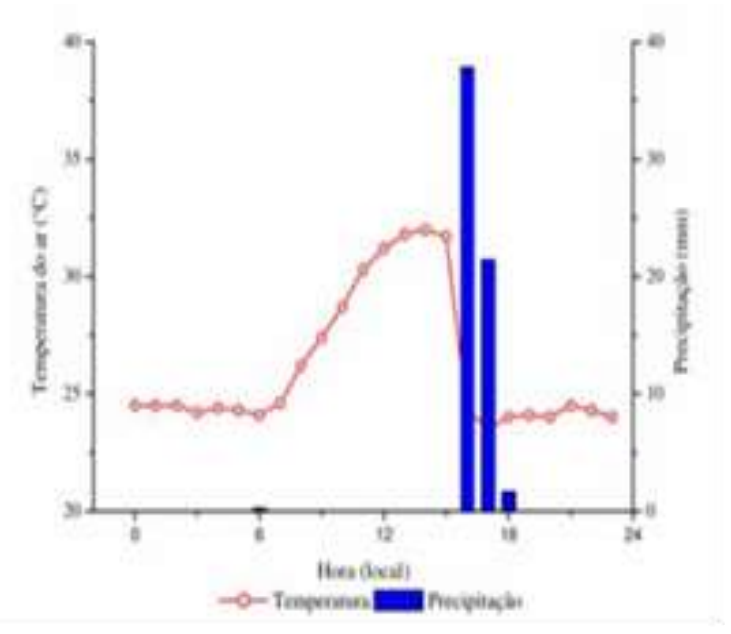

Figura 8 - Chuva ocorrida no dia 09/05/2011. Fonte: Araújo et al. (2012).

Visando tornar o estudo da bacia mais realista e completo, e analisar seu comportamento quando solicitada em capacidade máxima de armazenamento, associa-se a este evento de chuva severa, as cotas de tábuas de maré, fornecidas pelo Instituto Nacional de Meteorologia- INMET, para o horário do evento em estudo, visto que os canais dessa região sofrem influência direta de marés, inclusive sofrendo transbordos em dias de marés muito altas. Assim foram introduzidos dados referentes à curva de maré, onde se observa uma cota inicial de 3,15 m que vai reduzindo e atinge $1,98 \mathrm{~m}$ com três horas de chuva, conforme se figura 9.

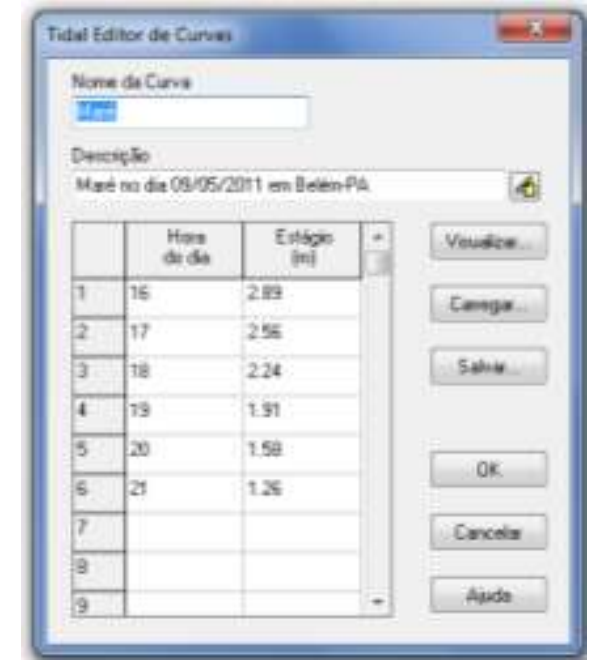

Figura 9 - Curva de Maré do SWMM alimentada com dados do INMET (2015).

Fonte: Autores, 2016.

Observe-se que a derivação existente na foz da bacia do Una, denominada Canal do Jacaré não foi considerada, portanto não está inserida nas análises.

\section{RESULTADOS E DISCUSSÃO}

\section{Resultados}

A simulação da bacia do Una foi efetuada considerando os canais em condições médias de manutenção, para representação de situação mais próxima da realidade atual.

A simulação da bacia do Una com o SWMM apresentou o resultado da Figura 10 mostrando que a simulação foi bem sucedida com erros mínimos de $-0,12 \%$ para escoamento superficial e de $-4,56 \%$ para propagação de vazão. 


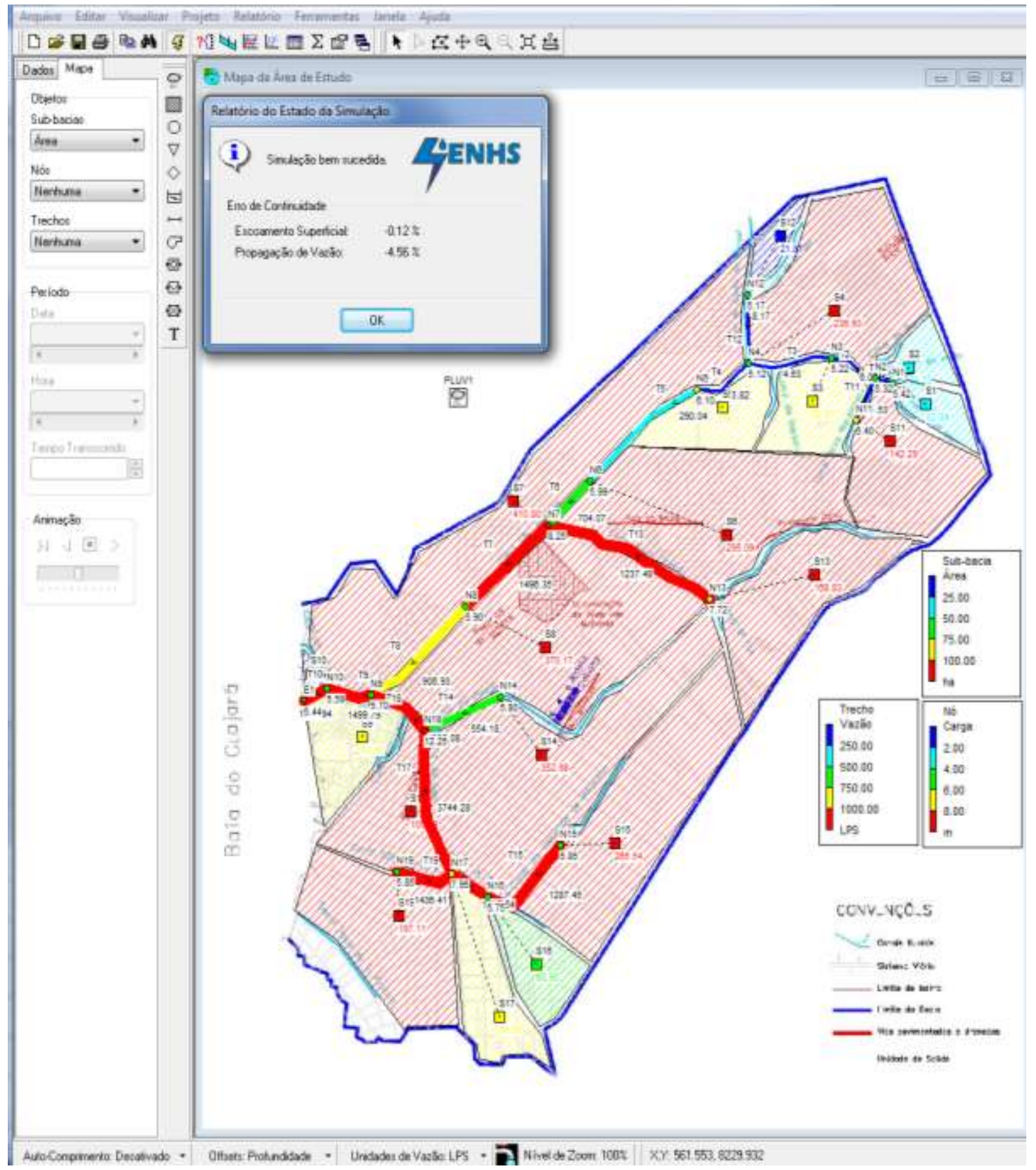

Figura 10 - Resultado de simulação da bacia do Una em Belém-PA. Fonte: Autores, 2016.

As figuras subsequentes resultaram da simulação da bacia do Una no SWMM e apresentam as seções longitudinais em momentos de nível d'água máximo, permitindo a visualização do escoamento nas junções e trechos de condutos.
A figura 11 apresenta o perfil do trecho que vai do canal da Nova Marambaia ao do Una (na área da comporta), que se estende da Rodovia Augusto Montenegro até a Rodovia Arthur Bernardes. 


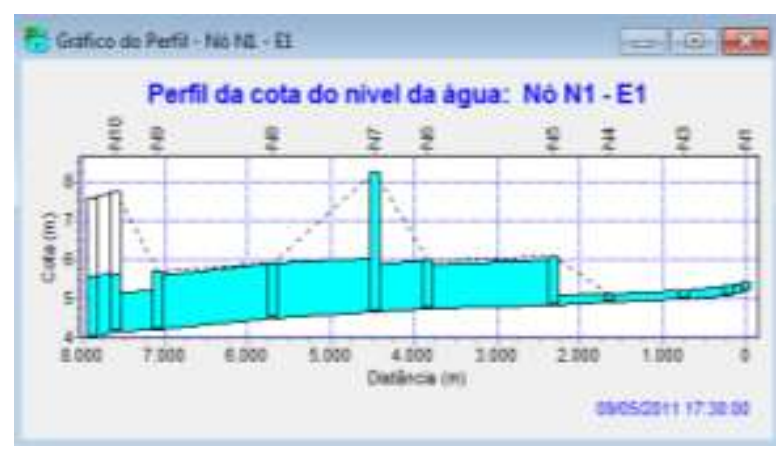

Figura 11 - Perfil da cota do nível d' água nos canais Nova Marambaia - São Joaquim - Una.

Fonte: Autores, 2016.

Observa-se que houve transbordo em todos os nós, à exceção do N10 e exutório E1. O nível máximo foi atingido às 17:30 hs.

A figura 12 mostra a simulação dos trechos entre os nós N15 e N9 e compreende os canais Visconde de Inhaúma, Antônio Baena, Galo e Una, com revestimento natural ou em concreto.

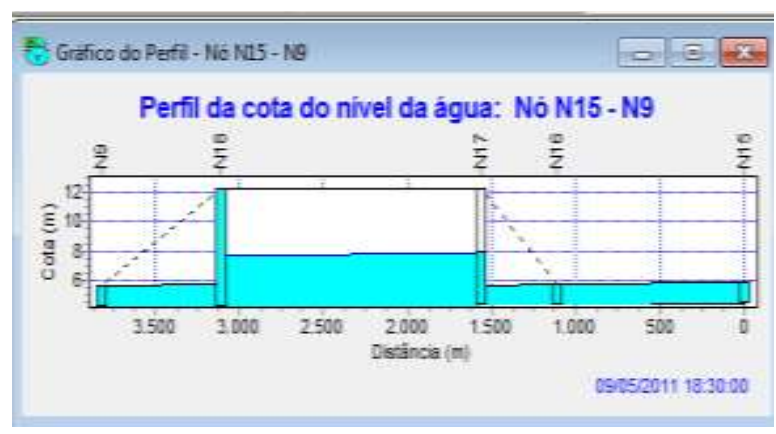

Figura 12 - Perfil da cota do nível d' água nos canais Visconde, Antônio Baena, Galo e Una.

Fonte: Autores, 2016.

Observa-se que só não houve transbordamento no nó N17, no canal do Galo, sendo o nível máximo atingido às 18:30 hs.

A figura 13 traz a simulação do trecho entre os N13 e N7, que diz respeito ao Canal Água Cristal, e cujo revestimento é pedroso com talude vegetado.

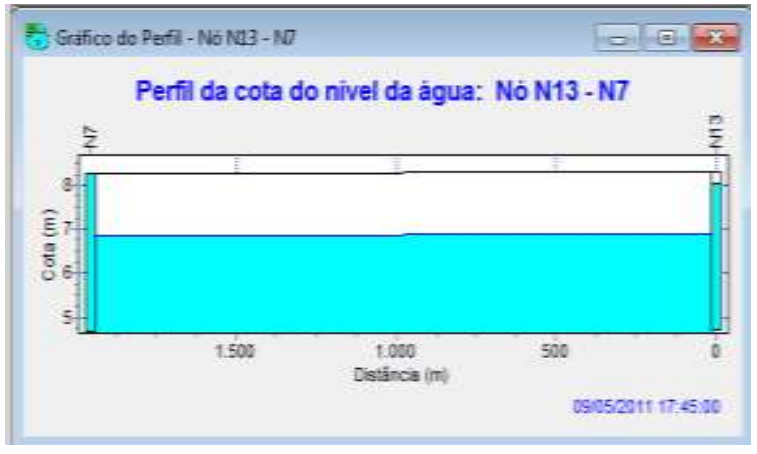

Figura 13 - Perfil da cota do nível d' água no canal Água Cristal.

Fonte: Autores, 2016.

Observa-se que o nó N7 apresenta transbordamento, sendo o nível máximo atingido às $17: 45$ hs.

A figura 14 mostra o trecho que vai do nó N14 ao N18, compreendendo o canal Pirajá, cujo revestimento é em concreto.

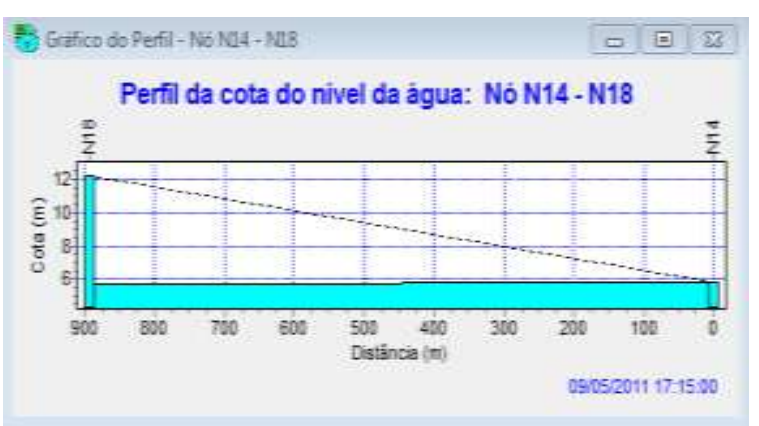

Figura 14 - Perfil da cota do nível d' água no canal Pirajá.

Fonte: Autores, 2016.

Observa-se que os nós N14 e N18 apresentam transbordamento, sendo o nível máximo atingido às $17: 45 \mathrm{hs}$.

A figura 15 mostra o trecho que vai do nó N12 ao N4, compreendendo o canal do Bengui, cujo revestimento é em concreto. 


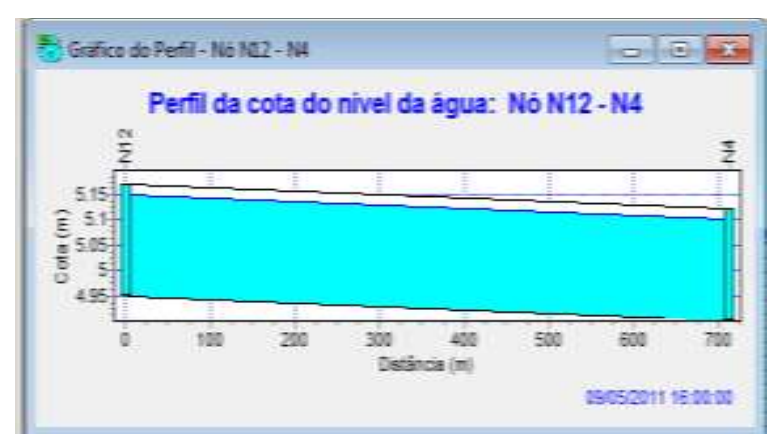

Figura 15 - Perfil da cota do nível d' água no canal do Bengui.

Fonte: SWMM, 2016.

Observa-se que os nós N14 e N18 apresentam transbordamento, sendo o nível máximo nas junções atingido às 16:00 hs.

A figura 16 mostra o trecho que vai do nó N11 ao N2, compreendendo o canal Nova Marambaia, cujo revestimento é em terreno natural.

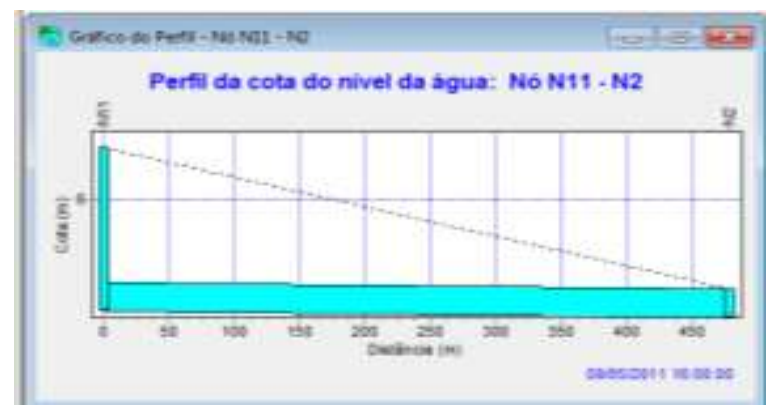

Figura 16 - Perfil da cota do nível d' água no canal Nova Marambaia

Fonte: Autores, 2016.

Observa-se que os nós N11 e N2 apresentam transbordamento, sendo o nível máximo nas junções atingido às 16:00 hs.

A figura 17 mostra o trecho que vai do nó N19 ao N17, compreendendo o canal São Carneiro, cujo revestimento é em concreto.

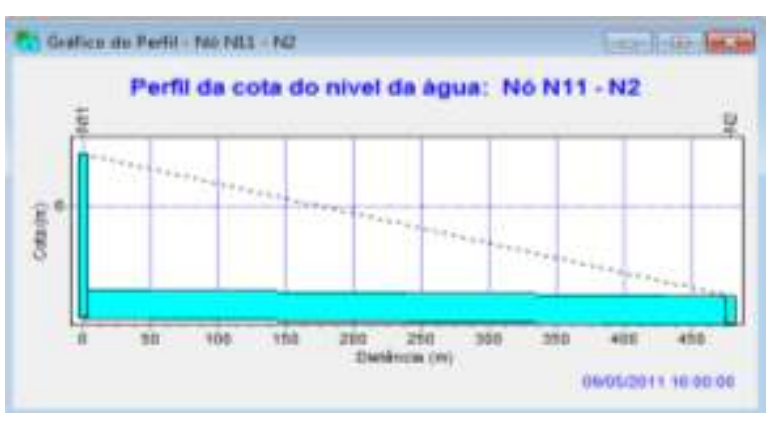

Figura 17 - Perfil da cota do nível d' água no canal São Carneiro.

Fonte: Autores, 2016.

Observa-se que os nós N19 e N17 apresentam transbordamento, sendo o nível máximo nas junções atingido às $16: 45$ hs.

\section{Discussão}

A simulação de eventos hidrológicos em bacias de drenagem urbanas com uso de softwares é de grande auxílio na gestão da drenagem urbana, e o alcance dos seus resultados é inegável. No entanto, mais do que simular fenômenos naturais em ambiente computacional, o seu melhor uso é no sentido de apontar modos de resolver ou minimizar problemas socioambientais urbanos a partir de seus resultados. No caso estudado, do ponto de vista da gestão da drenagem urbana, a ocorrência de alagamentos aponta a necessidade de melhoria nas políticas públicas municipais de drenagem urbana, com a adoção de medidas preventivas como a fiscalização para efetivamente combater o lançamento de lixo nos canais, o estabelecimento de limites máximos à área impermeabilizada em empreendimentos públicos e privados para minimizar o escoamento superficial, a inserção de bacias 
de detenção e retenção, estes concebidos para serem incorporados à paisagem urbana, com $\mathrm{o}$ uso dos conceitos de sustentabilidade urbana à água (BROWN et al., 2008).

Inicialmente, deve-se aprimorar a atuação dos poderes públicos, revendo $\mathrm{o}$ planejamento municipal e melhorando-se a legislação: planos diretores e códigos de obras. Deve-se, reforçar-se a fiscalização de empreendedores, garantindo-se obedecer as normas e, com isso, que grandes desastres sejam minimizados ou evitados. Não existe magia para escapar-se dos alagamentos, porém algumas mudanças na estrutura das cidades podem minimizar esses acontecimentos. O principal desafio é a adoção de medidas inteligentes que contribuam para minimizar a impermeabilização do solo e o assoreamento dos canais, já que as chuvas não são controláveis, enquanto que esses fatores socioambientais o são.

Assim, para a gestão urbana, o que é realmente importante é a discussão dos problemas sob o ponto de vista da cidade e o delineamento de cenários de intervenção para a minimização dos impactos dos fenômenos meteorológicos sobre a população. A simulação computacional, neste processo, passa a ser instrumental: um coadjuvante do processo de gestão e planejamento. (POLI, 2013).

\section{CONCLUSÃO}

A bacia do Una é a maior bacia urbana de Belém (PA), correspondendo a $60 \%$ da área total dessas bacias, sendo a mais importante do sistema de drenagem urbana dessa cidade. Apresenta problemas decorrentes da crescente urbanização, como ocupação desordenada e imprópria em áreas suscetíveis a alagamentos devido a baixas cotas altimétricas; aumento da área impermeabilizada e diminuição da infiltração, e por consequência, aumento da vazão e do escoamento superficial. Soma-se a isso a falta de conscientização da população ao lançar lixo doméstico no entorno e até mesmo dentro dos canais.

No estudo dessa bacia o modelo hidrológico SWMM mostrou-se muito valioso, pois possibilitou estudar o comportamento da bacia quando submetida a uma chuva severa ocorrida no dia 09/05/2011, com precipitação de $62 \mathrm{~mm}$ em um tempo de 3 horas, que resultou em transbordamento nos canais da bacia, sendo identificados pontos críticos passíveis de alagamentos, sugestivos de adição de reservatórios de detenção ao sistema de drenagem estudado.

Os resultados deste estudo justificam a necessidade, de forma diferenciada, de cuidados e atenção tanto por gestores públicos quanto pela sociedade principalmente nos trechos que apresentaram transbordamento, inclusive com a criação de medidas preventivas, não estruturais, como a 
fiscalização municipal para combater $o$ lançamento de lixo nos canais, sendo comum encontrar-se lixo doméstico no entorno e até dentro dos canais, fato que contribui para os frequentes alagamentos.

Conclui-se, portanto, que este estudo justificou sua importância, ao demonstrar que a associação de altos índices pluviométricos, características do relevo, clima, solo, elevação das marés, o intenso processo de urbanização e ainda o uso inadequado dos canais pelos moradores do entorno, contribuem para a elevação do escoamento superficial e para a ocorrência de alagamentos e inundações.

Destaca-se que o exutório da bacia do Una apresenta uma derivação chamada

\section{REFERÊNCIAS}

ARAÚJO, S.R.V.; SANTOS, A.P.P.; REIS, J.S. \& ROCHA, E.J.P. (2012). Precipitação severa em Belém do Pará: estudo de caso. In Anais XVII Congresso Brasileiro de Meteorologia - CBMET. Belém: CBMET. Recuperado em 09/12/2012, de www.eventweb.com.br/cbmet2012/cbmet201 2_12474_1344292018.

BELING. F.A. (2013). Análise do desempenho do Modelo SWMM 5.0 acoplado ao calibrador PERT na bacia do Arroio Cancela/RS (Dissertação de mestrado). Universidade Federal de Santa Maria. Santa Maria-RS.

BRASIL, S. C. (2004). Projeto de macrodrenagem da bacia do Una e índice de qualidade de vida de seus moradores (Dissertação de mestrado). Universidade Federal do Pará. Belém.

BROWN, R.; KEATH, N; WONG, T. Transitioning to water sensitive cities:
Canal do Jacaré, que não foi incluído nas simulações, e assim apresenta-se como um importante objeto de estudo para futuras pesquisas.

Além disso, considerando que este modelo atendeu as exigências para a qual foi utilizado, sugere-se para pesquisas futuras o uso do mesmo para a realização do estudo do comportamento hidrodinâmico nas demais bacias hidrográficas existentes em Belém, para que assim seja possível realizar a comparação entre todas as bacias na perspectiva de demonstrar quais se mostram mais eficiente enquanto sistemas de drenagem urbana, e quais apresentam mais pontos críticos.

historical, and future transition states National Urban Water Governan. In: $11^{\mathrm{a}}$ International Conference on Urban Drainage, Edinburgh. Anais. Edinburgh Scotland, UK, 2008.

CARDOSO, M. S. S., MÜLLER, S. C., DUARTE, A. A. A. M., \& LIMA, J. J. F. (2014). Ações de regularização fundiária e de mensuração das desconformidades urbanas: o caso das terras da União sob a tutela da Universidade Federal do Pará na cidade de Belém (PA). urbe. Revista Brasileira de Gestão Urbana, 6(3), 275-287. http://dx.doi.org/10.7213/urbe.06.003.AC03.

Frente de Moradores Prejudicados da Bacia do Una - FMPBU (2015). MICI-BR-2013076. Recuperado em 28/10/2015, de idbdocs.iadb.org/wsdocs/getdocument.aspx?d ocnum $=38648873$.

GARCIA, J.I.B. (2005). Monitoramento Hidrológico e Modelagem da Drenagem Urbana da Bacia Hidrográfica do Arroio Cancela. (Dissertação de mestrado). Universidade Federal de Santa Maria. Santa 
Maria.

Instituto Brasileiro de Geografia e Estatística

- IBGE (2011). Censo Demográfico 2010: características da população e dos domicílios - resultados do universo. Rio de Janeiro: IBGE. Recuperado em 02/11/2015, de www.biblioteca.ibge.gov.br.

Instituto Brasileiro de Geografia e Estatística - IBGE (2014). Perfil dos municípios brasileiros 2013. Rio de Janeiro: IBGE. Recuperado em 02/11/2015, de www.biblioteca.ibge.gov.br.

Instituto Brasileiro de Geografia e Estatística - IBGE (2016). Bases cartográficas 2016. Rio de Janeiro: IBGE. Recuperado em 14 de julho de 2016, de mapas.ibge.gov.br/bases-ereferenciais/bases-cartograficas/cartas.html.

Instituto Nacional de Meteorologia - INMET (2015). Parâmetros

Meteorológicos Mensal. Brasília: INMET.

Recuperado em 05/11/2015, de www.inmet.gov.br.

POLI, C.M.B.. As causas e as formas de prevenção sustentáveis das enchentes urbanas. Passo Fundo-RS: $2^{\circ}$ SNCS. Recuperado em 03 de novembro de 2016, de https://www.imed.edu.br/Uploads/As\%20caus as $\% 20 \mathrm{e} \% 20$ as $\% 20$ formas $\% 20 \mathrm{de} \% 20$ preven $\%$ C3\%A7\%C3\%A3o\%20sustent\%C3\%A1veis $\% 20$ das $\% 20$ enchentes\%20urbanas.pdf.

Prefeitura Municipal de Belém - PMB (2015). Dados da Cidade. Belém: PMB. Recuperado em 25 de outubro de 2015, de www.belem.pa.gov.br/planodiretor/paginas/br asao.php.

RIBEIRO, E.G.P.; FERREIRA, B.M.; MACIEL, M. N. M.; PEREIRA, B.W.F.; SOARES, J.A.C. (2015). Caracterização morfométrica da bacia hidrológica do
Igarapé do Una por meio de geotecnologias. In: Enciclopédia Biosfera, v. 11, n. 21, p. 2970.

SOTÃO, P.R.N.B. \& HENNIG, M.H.R. (2013). Aplicação do simulador hidrológico SWMM em um canal da bacia hidrográfica do Una em Belém-PA. (Trabalho de graduação). Universidade da Amazônia. Belém.

SILVA, R.R.M. (2004). A ampliação de obras civis e de Saneamento na Bacia do Una em Belém do Pará e as condicionantes relacionadas às características geológicas e geotécnicas. (Dissertação de mestrado). Universidade Federal do Pará. Belém.

Storm Water Management Model - SWMM. (2012). EPA SWMM 5.0 - Modelo de Gestão de Drenagem Urbana. Tradução de Laboratório de Eficiência Energética e Hidráulica em Saneamento. Campina Grande: UFPB. Recuperado em 25/03/2014, de www.lenhs.ct.ufpb.br/html/downloads/swmm/ SWMM_2012.pdf.

SHINMA, T. P. (2011). Calibração multiobjectivo do SWMM aplicada à transformação chuva-vazão. (Dissertação de mestrado). Escola de Engenharia de São Carlos da Universidade de São Paulo. São Paulo.

TARGA, M. S.; BATISTA, G. T.; DINIZ, H. D.; DIAS, N. W.; MATOS, F. C. (2012). Urbanização e escoamento superficial na bacia hidrográfica do Igarapé Tucunduba, Belém, PA, Brasil. Revista Ambiente e Água, 7(2), 120-142.

(http://dx.doi.org/10.4136/ambi-agua.905).

TUCCI, C. E. M. (2002). Gerenciamento da drenagem urbana. RBRH. Revista Brasileira de Recursos Hídricos, 7(1), 5-27. 